\title{
APPLICATION OF 3D DESIGN TECHNOLOGY IN THE CONSTRUCTION OF 220KV MILUOXI SUBSTATION
}

\author{
JIANG Wen ${ }^{1 *}$, YANG Jin $\mathrm{Hu}^{1}$, ZHAI Wei ${ }^{1}$, XU Guangbing ${ }^{1}$, XIANG Xinxin ${ }^{1}$, DU Boyang ${ }^{1}$ \\ ${ }^{1}$ Hubei Electric Engineering Corporation Limited, 430040, Wuhan, China
}

\begin{abstract}
In this paper, through the application of 3D design technology in the construction of $220 \mathrm{kV}$ Miluoxi substation, the main aspects of the application of 3D design technology in the construction are summarized, including inter discipline verification, collision inspection, real scene modeling, equipment 3D installation details, 4D construction simulation, VR technology application and mobile application solutions. This paper also summarizes the economic, management and social benefits of three-dimensional application, which can be used as a reference for the following projects.
\end{abstract}

\section{Introduction}

The traditional substation construction management is divided by project department, and the relevant professionals are responsible for each part. The lack of communication between professionals often leads to many problems, such as the discrepancy between the reserved holes in civil engineering and the actual electrical installation position. In the actual construction process, if a link is stopped, it will affect the whole construction process, especially the schedule control, quality control and cost control. At the same time, because the construction drawings are not intuitive enough, the construction plan is not expressed carefully, in the construction process there will inevitably be problems of delay and rework, resulting in waste of cost, delay in the construction period, quality can not be guaranteed, and so on. ${ }^{[1]}$

In order to strengthen the Substation Project Life Cycle Management Concept, leading the development direction of lean management in the construction field, it is necessary to explore the method of using the results of 3D design to guide project site schedule management, quality management, technical management and safety management. It solves the problems of unclear professional interface, scattered data management and difficult interactive handover during project construction. $^{[2]}$ The novel $3 \mathrm{D}$ digital way has a good prospect in the substation project construction management. Exploring the digital construction management concept is the development direction of digital management in the whole process of substation project construction in the future. ${ }^{[3-5]}$

\section{3D Design Of Miluoxi 220kV Substation Project}

\subsection{Project Profile}

Miluoxi 220kV substation is located in Shiniu Village Gupei Town, Miluo City of Hunan Province, $6.3 \mathrm{~km}$ north of Miluo City, $15.8 \mathrm{~km}$ east of Beijing-Zhuhai Expressway Pingjiang West entrance, $20.8 \mathrm{~km}$ northwest of Yingkou Town. Both $220 \mathrm{kV}$ and $110 \mathrm{kV}$ terminal and current phase are connected by double bus. Single bus three-section connection is adopted in the final phase of $10 \mathrm{kV}$, and single bus connection is adopted in the current phase. The main transformer adopts three-phase three-winding on-load voltage regulating oil-immersed self-cooling high impedance transformer, GIS combination electrical appliances are used for 220 and $110 \mathrm{kV}$, and metal-armored indoor switchgear is used for $10 \mathrm{kV}$. The construction scale is shown in Table 1.

Tab. 1. The construction scale of Miluxi 220kV substation

\begin{tabular}{c|c|c|c}
\hline No & Item & $\begin{array}{c}\text { Current } \\
\text { Period }\end{array}$ & Terminal \\
\hline 1 & $\begin{array}{c}\text { Main } \\
\text { Transformer }\end{array}$ & $1 \times 180 \mathrm{MVA}$ & $3 \times 180 \mathrm{MVA}$ \\
\hline 2 & $220 \mathrm{kV}$ Line & 2 Lines & 8 Lines \\
\hline 3 & $110 \mathrm{kV}$ Line & 6 Lines & 12 Lines \\
\hline 4 & $10 \mathrm{kV}$ Line & 10 Lines & 24 Lines \\
\hline 5 & $\begin{array}{c}\text { Reactive } \\
\text { Compensation }\end{array}$ & $\begin{array}{c}3 \times 10 \mathrm{MVar} \\
\text { Capacitor }\end{array}$ & $\begin{array}{c}9 \times 10 \mathrm{MVar} \\
\text { Capacitor }\end{array}$ \\
\hline
\end{tabular}

This project depend on the State Grid Corporation outdoor GIS general design scheme. Both $110 \mathrm{kV}$ and $220 \mathrm{kV}$ GIS equipment adopt the "combined sail type" off-line mode. The whole substation truss and equipment

*jiangwsj@powerchina-hb.com 
support, power distribution unit building, guard room, main transformer firewall and hydraulic structures are designed and constructed according to the assembly scheme. The project is the support project of the 2017 3D Design Competition and one of the first 3D design pilot projects of the State Grid Corporation of China. The preliminary design review was completed in April 2018, the official construction started in September, and the official completion and production began in June 2019.

\subsection{Platform Application}

This project is based on the Bentley platform. The main application software includes: collaborative design PW module, electrical and civil engineering modeling modules, real scene modeling, rendering modules, construction and application modules Synchro Pro.

\subsection{Three-dimensional design}

This project is the first batch of substation projects for the State Grid Corporation to carry out the three-dimensional design of construction drawings. Through Benteley platform, it has realized the collaboration design of electrical primary, secondary, general drawings, architecture, structure, water supply and drainage, ventilation and air conditioning, and established the electrical main wiring logic model and 3D layout model. The three-dimensional model of this project covers the geographic information of the whole station, gates, roads, cable trenches, power distribution devices, secondary equipment compartments, secondary screen cabinets, whole station structure supports and equipment foundations, $10 \mathrm{kV}$ cables, underground pipe networks, HVAC and outlets terminal tower, etc., It is shown in Fig. 1.

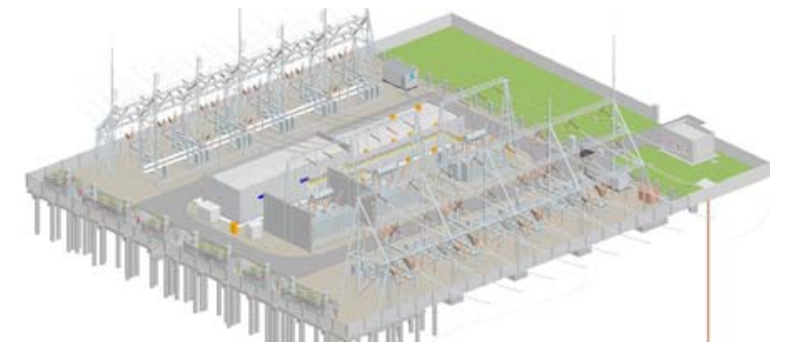

Fig. 1. Total station model

Based on the three-dimensional design model of this project, analysis and calculations such as three-dimensional electrical safety net distance verification, three-dimensional lightning protection verification (Figure 2), fine cable laying design, intelligent terminal wiring design, mechanical analysis and earthwork balance calculation were carried out. Integrating the layout model of the whole station, carrying out comprehensive collision inspection, and extracting the plan view and material table through the model.

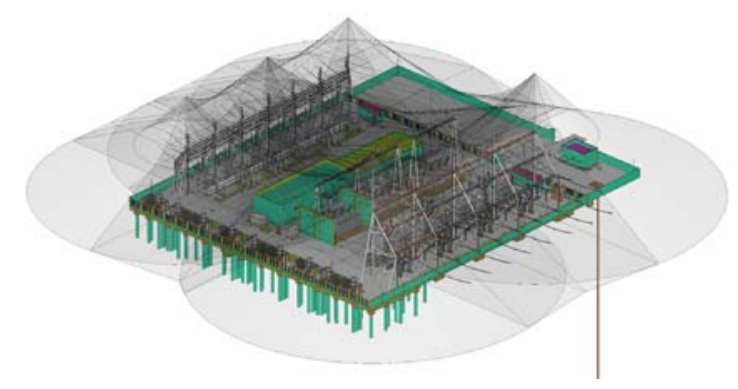

Fig.2. Lighting protection model

\section{Application of three-dimension design technology in construction}

The preliminary design and construction drawing design of Miluoxi $220 \mathrm{kV}$ substation project adopted three-dimensional design.The application of three-dimensional design in construction has been fully explored.

\subsection{Inter discipline verification}

Through reviewing the layout of $220 \mathrm{kV}$ GIS equipment by the electrical primary professionals reviewed, it was found that the equipment foundation of the No. 2 main transformer bay was missing (Figure 3). It's due to the structural designer's omission during modeling.

Through the review, a total number of 8 similar problems were found, effectively reducing the design errors.

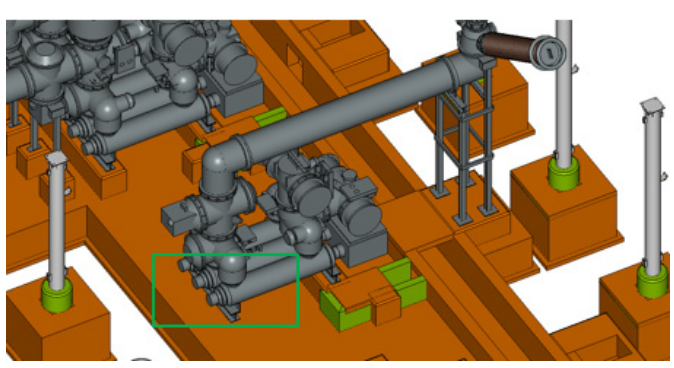

Fig.3. The model of missing GIS foundation

Through the review, the professionals of structure found that the Cage for ladder of $110 \mathrm{kV}$ frame was too low and collided with the walkway railings on the beam (Figure 4). The climbing ladder collides with the column head connector and flange, and it was improved immediately after proofreading. The structural review also found that the canopy beams and column stiffeners, and the canopy beams and roof beams collided with each other. Through the review, a total number of 11 similar problems were found, resulting in avoiding processing rework and changes. 


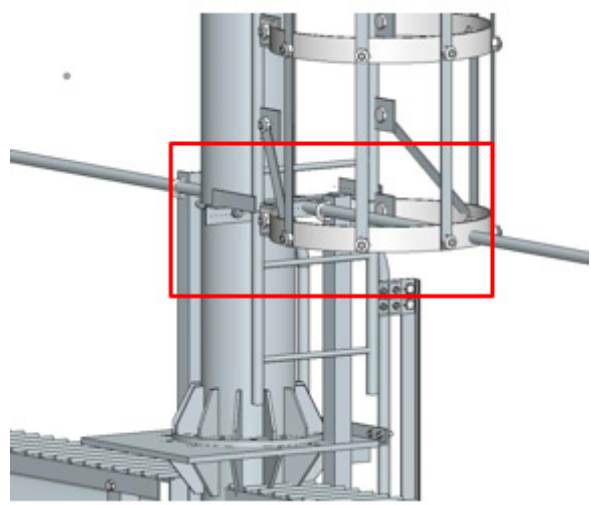

Fig.4. The low the Cage for ladder of frame

Through the review, the HVAC professionals found that there were deviations in the foundations of the building and structure professional houses, and the fans could not be accurately aligned (Figure 5). It has been found that there are differences in the reference points of the architectural and structural professional elevations, which shall be adjusted and corrected after verification. The review also found that the outdoor unit of the house and ground air conditioner was deviated from its base. A total number of 7 similar problems were found in the review of the general plan and plumbing, and they were immediately improved after the review.

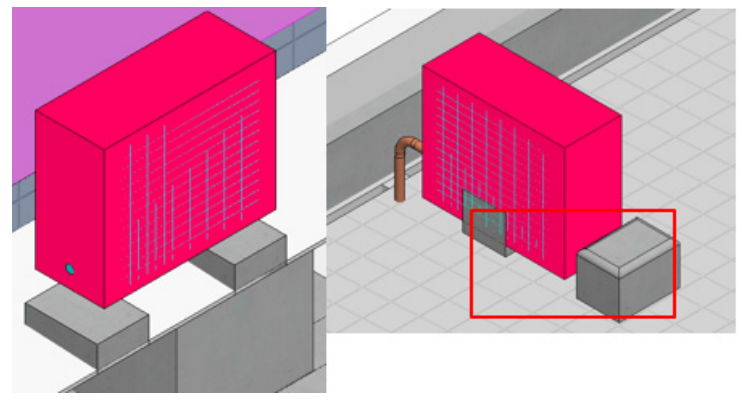

Fig.5. The deviation between the outdoor unit of ground air condition and its foundation

\subsection{Comprehensive collision inspection}

Integrate various professional layout models, carry out comprehensive collision inspections, quickly and accurately detect the location and number of collisions, and form collision reports (Figure 6 and Figure 7), reduce later engineering errors, and find a total of 30 collisions between professionals, effectively avoiding rework in later stage.

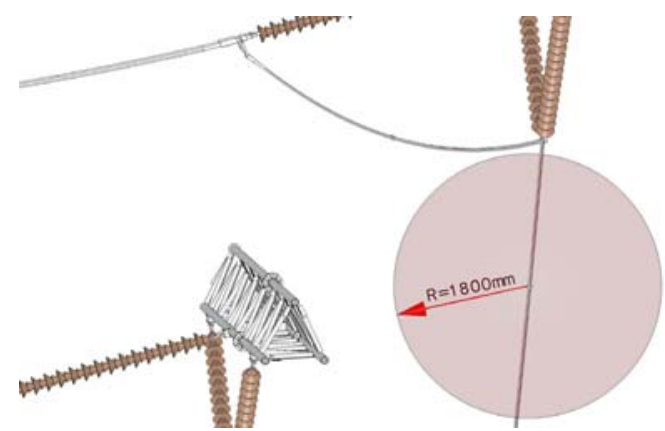

Fig.6. Space charging distance check

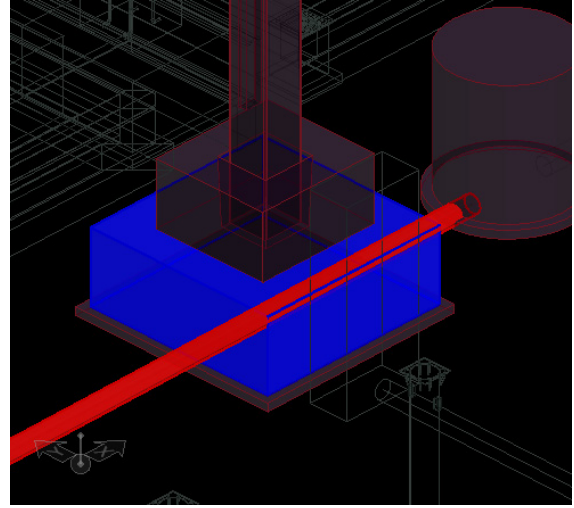

Fig.7. Collision between foundation and pipe

\subsection{Application of real scene modeling technology}

DJI drones are used for aerial photography around the site, and high-precision real scene models are automatically generated through air three calculations (Figure 8). Compared with traditional two-dimensional drawings, the real scene model can directly reflect the topography, vegetation, rivers and lakes, roads, houses and other information of the site area, which providing reliable environmental information support for substation site planning and selection, large-scale transportation conditions, and outgoing corridor planning.

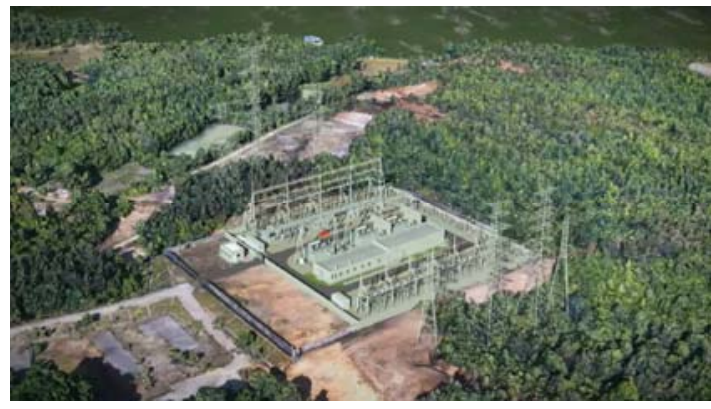

Fig.8. The total station model based on real scene

\subsection{Application of equipment 3D installation details}

The detailed assembly model is converted into a common PDF format. Combined with annotations and instructions, it can display details conveniently and flexibly. After installing the professional version of PDF on the computer, the 3DPDF three-dimensional model can be used to integrate dynamic construction simulation (Figure 9), guide the construction unit in construction preparation, construction disclosure and on-site installation. 


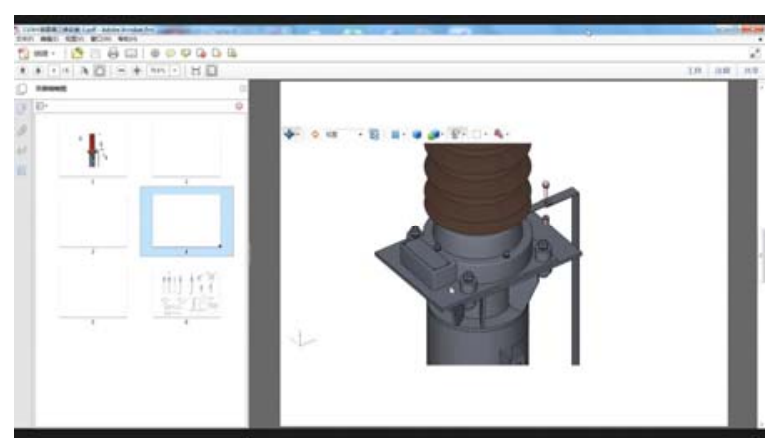

Fig.9. 3DPDF installation details

\subsection{D construction simulation}

As an important part of power grid engineering, substation has a wide variety of equipment, complex line layout, and strong construction expertise. According to the level of pre-arrangement of the construction unit, in order to improve the construction management level of substations, the platform construction application software Synchro Pro is used to build 4D construction simulation animation ( Figure 10).

Through the model and construction progress information association, 4D simulation animation can simulate the plan, history, and current construction progress can be 3D simulation of the whole construction process in time and space, and the growth and color change of the model can be realized through the leveling and civil construction of the construction. The real-time status changes of each element in the electrical stage, and automatically analyze the comparison results, intuitively understand the progress of on-site construction, present information that cannot be clearly expressed in text and percentage values, and intelligently represent physical objects and information parameters.

The 4D simulation animation can instantly show the construction progress cross-line diagram, construction site operation flow and procedures (Figure 11). Construction management and construction units can use the functions of 4D construction simulation such as visualization, coordination, simulation, and optimization to systematically and comprehensively manage and control the site, and correct schedule deviations in time.

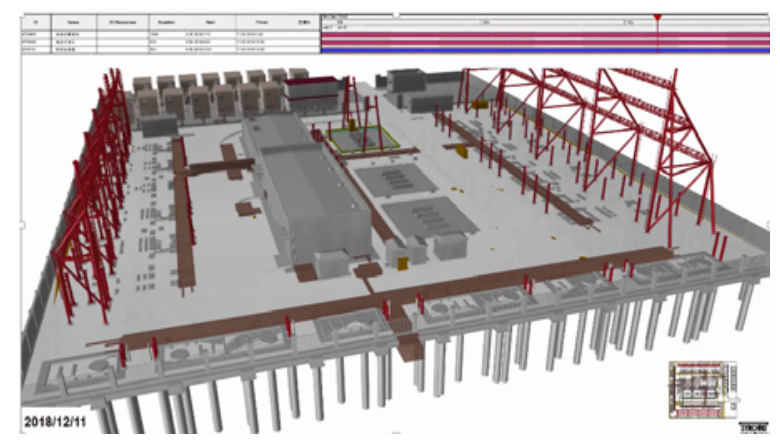

Fig.10. Lighting protection model

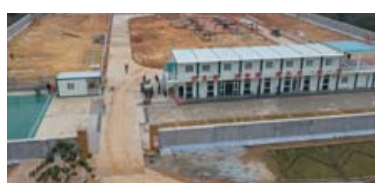

comparison and bias Lagging:

Accident Oil Tan and pipes: not started Firewall: not started

The main Transformers Foundation: not The main
started

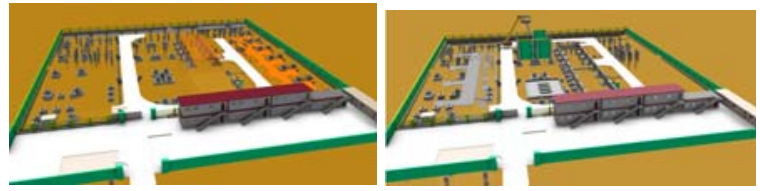

Fig.11. 4D simulation animation

\subsection{VR technology application}

Site-wide roaming VR technology in the virtual reality environment, by loading a three-dimensional real scene model in the virtual reality environment, construction management and construction personnel can realize the virtual scene roaming of the real geographic information model (Figure 12). Through this way of roaming, the construction management and construction personnel interact with the real environment in an immersive sense, understand the design intent to the greatest extent, and verify the feasibility of the design content.

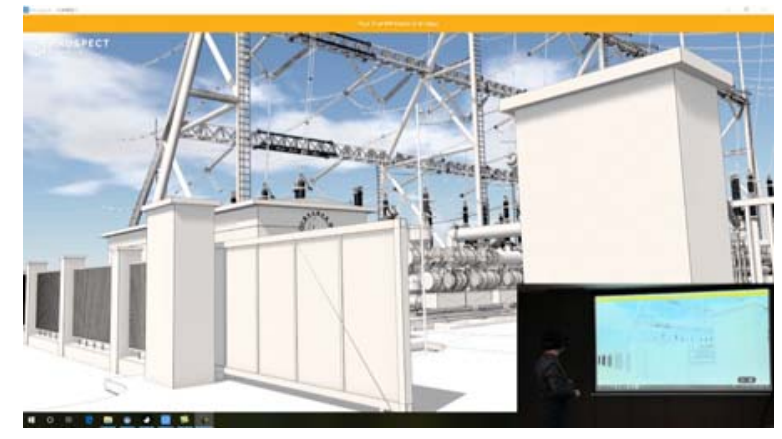

Fig.12. VR technology application

\subsection{Mobile application solutions}

View the model through NavigatorMobile in the Ipad mobile terminal (Figure 13). Through multiple pre-stored viewports, the key position can be quickly switched and browsed. Through the cut of the 3D model, it can view the internal models of buildings and equipment compartments, and browse and roam the whole site model from the first perspective.

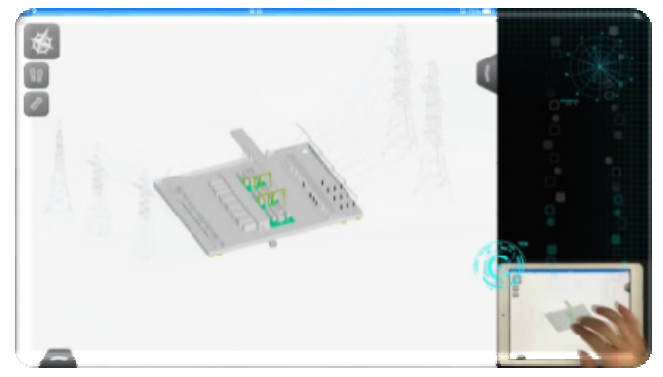

Fig.13. Application on ipad movable terminal

The 3D panorama of the project is released through the cloud, and the construction management and construction personnel can scan the $\mathrm{QR}$ code through 
their mobile phones and browse the 3D model of the project on the mobile terminal (Figure 14). The panoramic display has a strong sense of reality, good interactivity, strong sharing, and high cost performance. It is helpful for construction management and construction organization design, and on-site design clarification, understanding the intent of the design, construction schedule management and safety management.
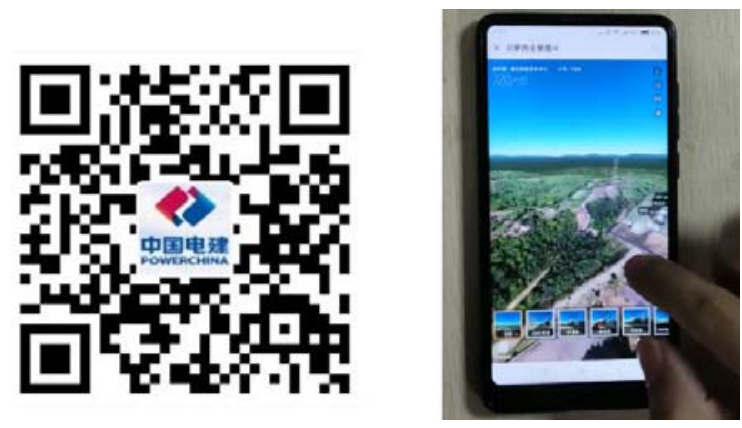

Fig.14. Application on mobile phone

\section{Construction and management construction application effectiveness}

\subsection{Economic benefits}

By applying the three-dimensional design results formed in the design stage to the whole process of substation engineering construction management, the repeated production of substation engineering models in the information work can be avoided, and the data basis for the application research of auxiliary construction management of substation engineering design results can be provided.

The exploration and application of 3D design in the construction, management and construction of this project effectively avoided more than 30 rework in the later stage, saved project changes by about 500,000 yuan, and saved design review time by about 65 days. The construction was completed 30 days ahead of schedule, resulting in an economic benefit of about 1.5 million yuan.

\subsection{Management benefits}

The three-dimensional design results of substation engineering assist the construction management application of the exploration results, realizing the electronic, digital and visualized substation engineering construction management, providing project managers with intuitive, real-time and effective auxiliary tools. Carrying out construction schedule simulation, it can integrate or combine with project plan management software to realize the visual management of project schedule and plan, so that the traditional plan management on the two-dimensional chart can be improved to the intuitive management level of different stages of definition and extraction of the three-dimensional physical model. It can also immediately provide a list of various equipment and materials required to define the model, accurately determine the engineering quantity, and facilitate the scientific and reasonable arrangement of construction force input, and more effectively organize the construction.

\subsection{Social benefits}

When connecting with various social classes, proprietors and other related units, it can display the construction process in a very visual, intuitive, three-dimensional, perspective, multi-angle, refined, and node-oriented manner.

Through the application of three-dimensional design results and the sharing of digital results, a systematic computer processing method is created to replace a large number of manual repetitive work and management methods. While saving a lot of social resources, it can also improve the efficiency of project construction and achieve good social benefits.

\section{Conclusion}

With the help of 3D visualization technology, Substation engineering results assisted construction management application research provides multi-dimensional comprehensive display of information. Even if the construction management personnel are not on site, the construction progress of the substation can be quickly grasped, the first-time information acquisition and feedback can be achieved.

With the comprehensive development of power transmission and transformation projects and the advancement of informatization construction, the construction of power transmission and transformation projects requires comprehensive and fast management methods. The use of three-dimensional design results to fully assist management and application in the process of project construction is precisely for the information construction. The deepening and expansion of the project also innovated the management subsection for construction and construction, providing necessary information support for the control and control of the project, ensuring the orderly progress of on-site management and construction, assisting leadership in decision-making, and accelerating the pace of construction management information construction. It has good prospects in the construction and management of power transmission and transformation projects.

\section{REFERENCES}

1. H.W. Cao, The Application of 3D Digital Technique in Basic Construction Management of Transformer Substation[J]. Shanxi Science and Technology, 2013, 28(02): 112-114.

2. J.B. Li, X. M. Liu, Qing Ye, etc.. Research on management and application of $3 D$ digital design in substation construction [J]. China Management 
Informationization, 2019, 22(18): 82-83.

3. J.M. Xiao. Application of $3 D$ Design Technology in Substation Design [J]. Low Carbon World, 2017(10): 38-39.

4. W. Wang. Application of 3D Digital Technology in Substation Design[J]. Electric Power Survey \& Design, 2018(S2): 67-68.

5. W. Qi, K.J. Chen. Research on Digitization and 3D Interface Design of Secondary System in Substation[J]. Zhejiang Electric Power, 2018, 37(2): 53-56. 